\title{
A Land Is Devoured by the Pervasive Deadly Corruption
}

\author{
Jakir Hossian \\ Department of Business Administration, Britannia University, Bangladesh
}

Copyright (C) 2015 by authors, all rights reserved. Authors agree that this article remains permanently open access under the terms of the Creative Commons Attribution License 4.0 International License

\begin{abstract}
A land is devoured by pervasive corruption has been studied well. A country without a leadership worsens corruption in society is the theme for this research writing has been presented with wider analysis and descriptions. Crimes or corruption are various in natures have been investigated from different aspects and facets. The leadership in Bangladesh from very inception of independence has been shaky, frail and instable. The third parties around the politics take ample scopes to create the vacuum of leadership. Finally some findings have been concluded in the final stage of the topic which heavily hinges on enormous salient facts including lacks of competences and worthiness of a leadership who fundamentally leads the nations in collaboration with other members of the government, and owing to failures in ensuring such onus and performances, the total systems of the national functions are corrupted and thus no parts of her mechanism work well. And the rest focuses on the characteristics of her subjects who, in spite of not being so involved in all facets of functions are directly or indirectly responsible for worst situations with their superfluous attitudes, superstitious belief, crime intent, timidity, dodge, pedantry, ego, folly, vices, ill motives and avidity. Besides feminists leadership roles for a long time, ill and loose governing capacity \& lawlessness have a huge impact on national instability and risk escalation.
\end{abstract}

Keywords Ignorance, Terrors, Feminism, Discrimination, Favoritism, Leadership, Politicizing and Corruption

\section{Introduction}

A land meaning Bangladesh got her independence in 1971 and almost 45 years have elapsed. The population has grown double within this period. The country makes its development in a normal ways as other similar nations grow. The population are nearly 18 crore, the $70 \%$ of people live in poverty. There are main sources of income are garments industries, agricultures, and producing products made of jutes and other materials. Education level is $80 \%$ as primary participants and certificates holders. $90 \%$ people are Muslims while other $10 \%$ are Hindu, Budha and Christians. The size of the country is 5500 kilo miles. As it is known as Bangladesh continuously faces varieties of major crisis like military coups, political turmoil, riots, usurping the power without legal mandate, and holding power by forces. We have the topic which is very wider and much complicated having a lot of overlapping within fields of socio-cultural, political, economical and educational issues. India is a neighboring country which surrounds three sides of the country. We need to anticipate the roles of phantom godfathers who control the politics and rules of Bangladesh. A consequential phenomenon of similar crisis is followed one after another. We now try to see the issues of problems looking into each trade / occupation and professional class of people who vary in their lives styles and activities which must help us realize the real contexts of the society. The natures and gravity of crimes are different but these are almost equally responsible for causing troubles to society. Classes of people are high class, lower high class, and middle class, lower middle class and lowest class. Basically the trades / occupations and professions are known to us all though, we need to glance over them briefly. Professionals are mainly Doctor, Engineer, Lawyer, Teacher ( primary, secondary, higher secondary, graduate levels) , Judge, Police( Detective, CID, Intelligence, RAB, Anti Corruption Commission, Ansar, BSB, and Special force) Army, Navy, Pilot, Air force, Psychologist, Anthropologist, Businessmen, Producers, Social worker / Human right activists, Registrar, Sociologist, Artist, Journalist, Politicians and Government, Customs officers Administrators, Banker, Accountant, Economist, NGOs, Landlords, Leaders, Nurse . Women and Youth roles are main in Bangladesh. Roles of God /religion, cultures, and economics are very much required for study too. Departments of government are also focused on study. The trades are office Secretary, Clark, Contractors, Driver, Craftsman, Technician, Auto taxi Driver, Rickhsa Puller, Hotel worker, Agriculture Labor, Industry Worker, Fishermen, Diggers, Miners, Farmers, Clergyman, Imam, Cooks, Chefs, Waiter, Hawkers, Salesman, Carpenters, Mason, Painter, Computer Operatives, Nanny, Attendant, Security, Horticulturist, Barber, Brick men, Goldsmith, Blacksmith, etc are main in Bangladesh . We will see how 
these professional and occupational classes are involved in activities and vices of corruptions.

\section{Literature Review}

Professional people who lead a team or office are dominant to determine the contexts in areas. We will now study the overall issues of the topic which is very significant one in terms of social development. We see time moves fast, no one cares about others in general because of every one's business and pressure for earning for own support for survival. Care for family, affection for siblings, respect for elders, and hospitality for relatives dry up on and on. How are these contexts reflected and happening in our environments would also be judged and examined here in this study? We now try to focus on lesser crimes involved in professions and then the graver ones are evinced. Religious services for various religions in Bangladesh are also seen here and there. These sorts of services men include Imams who preach in mosques, Clergymen in churches, Thakurs or Monks in temples are deprived class of society render their service with very less economical rewards and with no power or opportunity. They are fanatical in attitudes and cling to old belief. They are not largely harmful to our social entity.

Youth class and roles in Bangladesh have enormous involvements in perspectives like politics, social activities, economical issues and religious functions. However, youth class means those ranging ages from 12 to 22 years old. Ultimately they are future of the nation. They are grossly discriminated by the govt of Bangladesh and other external parties like UN funds or Wings. The youth (male) class do not receive free education like girls. They don't have stipends or other forms of assistance for education like girls. They do not have enough legal supports for any case that may need without fees or costs in courts like girls who take opportunity of free costs supported by govt for legal cases. There are many new girls' colleges / schools are being made in city areas but not many boys' schools or colleges are made for extra supports for increasing numbers of students day by day go up. The boys are hugely treated with disparity by the State laws. The same situations are seen in African Countries where these discriminations are newly imposed. The employments opportunities are similar in crisis. There are quotas for girls or women who apply for jobs are easily got but boys do not have jobs which they deserve. The girls who are not fit a position like Magistrate or Police superintendent are offered to girls. Because of all these biased situations against boys or males who are addicted, being thugs, and being terrorists, frenzied, the country goes back and corruptions are rampant.

The next professional class - teachers who are also deprived of opportunities, scopes, and power authority to misuse sources, as a result they are less in crimes or offense for commitments. We see some scenarios which make us doubt of their integrity. The financial scopes are sometimes misused by those who are in administrative positions. The feasible crimes in inciting students towards some movements for political benefits are seen. Using the students for their own interest, favoring some students with marks or grades are sometimes seen in this professional practices. Students are misguided and led to destructions by one class of vicious teachers at higher study levels. Personal skills and expertise or their lacking are not judged here.

Forces like Army, Navy and Air force are also targets of this study. We deal with many of them for data collection. These forces take opportunity or scopes for their own power and authority for use when they have ready power like coup or change of power from civilians in to regimental systems. Bangladesh is small and poor country where the budget for defense is very high and ambitious. The mid and high level officials use all luxurious cars, mansions, and other facilities which are unnecessary. The lower class staff does not get enough due facilities in forces is true. They suffer for their livihood. They misuse or abuse their power or opportunity by the time of coup. Assignation, murders, kidnap, abductions, extortions and sniper killings are hardly seen in their profession. Normally they are not involved in criminal activities except a few incidents which happen at higher positions from the rank of Captain to the top ranks. Now a days a new phenomenon emerges in contexts of Forces who are for national security and safety defense and their mind psychology, motivation, perception, attitude, aptitude , all veins and tissues of the brain are made of factors, thought and flesh of security capacity but their new motives and inclination towards building universities in each Camp / cantonment, Hospitals, Five star Hotels , Malls, Medical Colleges, Institutes are commercial and wise men's tasks rather than soldiers or sentry duty. They take full facilities and luxury from the public funds while the civilians live from hands to mouth without basic needs in the country. They take up new professions to gain more benefits within their main one ignoring its real values and onus. These are happening due to no or weak leadership.

Social workers or Human right workers -NGOs are the next professional classes who are now a day's more in practices engaging themselves in more core areas of society. The Human right workers or social workers are biased or prejudiced with the ruling class or external body who fund them. They are agents or spokesperson of certain group who make them do according to their (boss) wish or principles. The real human services are very much hampered and abused. Human rights workers are mainly attached to female class who are sometimes are victims but many times they exploit the opportunities and justice systems in society. They are involved in activities like promoting youth rights mean boys or girls rights and support them all but in reality they support only girls while boys are extremely avoided and deprived of scopes like educations, jobs, justice systems in courts. Boys receive no educational supports like free fees or charity but female students get free education up to graduate levels. These scopes are determined by public funds or outsides donations which are recommended by Human 
Rights or social work groups and accordingly the opportunities are offered. These groups are biased and partial to male class in many situations like presenting scenarios of society, telling the untrue issues of discrimination, degrading and demeaning male class mainly are noticeable. They seem to be right in developing economical state but basing on women class means narrowing down their efforts and which are obstructed by such issues of prejudices in actions. These human rights groups are formed by female members mainly.

The next class - doctors who are considered as the best service for society and seen as honest or serving humanity but the reality is based on motives of profits, interest in gain and high motivation for earnings. The knowledge in medicine practices are also lacking seriously. They charge very high like 500 to 1000 taka per patient for diagnosis. The rate for charges goes up day by day keeping up with other items of price hike. Those who work in public hospital are beyond reach by poor class of people. They normally serve in hospital for customary patterns but they examine patients at private chambers where they charge so high and make the patients run after them years after years for a cure of disease. These delays of cure are scopes for more earning because when the patients come, every time they pay fees though these fees are less than the first time. The conditions in service at hospitals are nondescript in terms of safety, hygiene or cleanliness which are totally out of standards. A sound man would be a patient once he visits a hospital. These conditions are due to the doctor's negligence, indifference, carelessness, lack of management and daredevil attitudes. There are facts that are related that sometimes doctors willy nilly kill patients.

Other positions are Banker and Accountant professional's commitment to crimes is not less than those are described above. The banker profession is totally involved in financial dealing which is very sensitive in view with measuring the importance of money and possession of money. Crimes are revolved around money sources. Banks are main sources of money and it is not that who work in bank are moneyed but those who administer banks facilitate money to criminals or their favorite ones or take bribes and offer money in forms of loans or other categories. The bankers or owners of banks don't offer loan to poor people who cannot repay, who are poor and ultimately remain poor, going back as poor being exploited and suffocated by poverty pressure. Accountant is professional who is not very much involved in grave crimes but financial misappropriation or embezzlements are noticeable in smaller scales at offices or companies.

Occupational classes are mainly fewer ones are not directly involved in crimes, office Secretary and Clark have ample opportunities of abusing and misusing sources of funds for displacing, misinterpretations of communications, distortions of messages, communications keeping hidden from top officials, and ultimately destroying lot of scopes and prospects for the company or departments. They do such issues as they are made or offered bribes or they use the scopes for offering jobs to their relatives are influential positions held by them. All communications are powers and these controlled by them. Government offices have serious influences of these positions and misuses of scopes are reported.

We now try to consider another profession is Journalism and media professionals which are ideal paths to serve people or society. It is noticeable that the present situations in the country become so worse that no moral principles work on their mind seen in many cases and incidents. The time from 2008 and till now 2016 is the worst history for the country where the utter deadly scenes are seen committed by many others including journalists? The media means TV, Radio, Press which are nearly 50 TV channels work in the country. Of all nearly $60 \%$ medias work for ruling class or government. Whatever Govt or ruling class commits reported to be fair. There are almost 3000 people killed by Forces and terrorists who under the shelter of govt perpetrate anything according to their whim during the period of governance. Some medias which are against those gangs and groups are banned, tortured incessantly. Coverage of news are distorted, changed and exaggerated in favor of govt. Killings reports, assassinations, abductions, group killing like in a family 5/6 members killed, tortures are reported based on biased and routine focus of report on opposition or rivals groups. The journalists make reports look untrue normally because supposing they go to spot of a killing or murder or abduction, they instantly decide or declare the name or body of criminals or killers who are not real ones. It is not their responsibilities to judge a murder case which is very complicated and mysterious need a lot of investigation and judgments. Uses of the language by the journalists are also frivolous and volatile. Their words and reports make huge differences and change in contexts which might cause havoc to opposite groups who may be innocent or not. Dramas, movies or films makers are addicted to only love scenes of lovers, who dominate over the $90 \%$ movies or dramas due to ignorance and limits of knowledge of them. The set story like Hero is mad of heroine, who is a rich family daughter whose father does not want to marry her to that poor lover. Or the story is sometimes opposite one. They highlight the glamour, beauty and adoration female characters as mediaeval contexts were made. The whole youth community is obsessed and attracted to such trash of love made of insanity and folly.

Engineers / technical contractors are the next one to be seen in contexts. They are all not similar to one another. Especially civil engineers are having lot of scopes for exploitation, abuse and misuses of funds. They get contracts for constructing bridges, houses buildings and highways which are big deals of money. They don't spend enough money which are really needed for the purposes. They use weaker, cheaper, fake materials which don't last long and ultimately the utility of the products are very shallow and damaging. There are many instances which show the uses of materials are weak and fragile bring destructions.

The next professional practice is business people who 
among all professions hold nearly $70 \%$ activities as majority private class of professionals in the country. There are varieties of business ranging from very smaller like footpath shop to very larger one like Industry. Their roles, onus, ranges of activities vary hugely. There are some business which are producers, manufacturers and then whole sellers, retailers, stores, middlemen, agents, direct sellers, displays centers, and distributors, shops owners are all business people. These professional people come from various roots and bases have no specific background of educational bases. Most people of this class are normally out of norms, values, principles, ethics and social responsibilities. They only understand earning, profits, interest and benefits. They charge prices for an item double or triple value, they decide what prices are, there is no marks of price level for a fix level. The electricity company is one deals with huge fund of the country. The bill of electricity for a small family normally costs 300 taka but the majority landlords charge 600 to 800 taka. The bills for electricity are falsified and forged in league with the help of electric technicians or office. The land lord offers very less costs to electric authority while they charge double costs with the tenants. The bills are made by secret deals between two parties are landlord and electric power authority. The other way to do so is to connect the lines of some parts of landlords to the lines of tenants. As a result more bills for tenants because of landlords' bill also added to the tenants finally. The power authority set a routine bill amount for a tenant, and that sort of bill come month after month not based on utility of measurements. Who are taking additional extra money from these bills which are collected from billions of families? There are load shedding in many parts of the country which means average 5 hours in a day no electricity and 150 hours in a month with no electricity but the same bills or more bills are paid. Why? The same way gas utility is hampered due to no/ very less supply of gas in a day but the authority take full charge of bills. The most people under poverty levels are $70 \%$ whose monthly incomes are ranging from 5000 taka to 15000 taka means 50 Euros to 150 Euros but most house buildings are built with 3 beds or more and their rents costs nearly 15000 taka mean 150 Euros. How do these live? There are $20 \%$ small sizes old houses are available, very limited for people to use. Governments are dumb and blind here. A family with $5 / 7$ members are suffocated for such severe crisis in housing. The most land lords behave tenants like extorters and butchers. The price hikes for all categories of items or foods and consumption items are not controlled by Government authority or laws. There is no government presence looks like in a country to control such suffocating contexts and conditions for middle, lower middle and lowest levels class of society. Producers increase price 5 taka for an item costs 50 taka, the local sellers increase the prices for that item 20 taka extra means 70 taka for a vegetable item per $\mathrm{kg}$.. Most People are unscrupulous charging prices for items; they raise prices instantly without any reasons or causes. These conditions have no fixed time or dates or bases. Whatever the business people decide on prices, people are bound to buy for those prices. One class of rich people buy whatever the prices and then the price get established. Ordinary people who are $60 \%$ in the whole country are chained and gagged, who can do nothing. The price hike or any other unfair issues happen, no one protests, people are like lotus eaters. It is reported that businessmen used to pay big amount of donation / money to the political thugs per month and they need to raise the prices of products is the reason. The pharmaceuticals companies produce medicines are core value of life but these medicines are fabricated, polluted by mixtures of low and dirty ingredients of raw products. There is no any mark of standards and price limits in this business too.

The educational Business is not excluded from this discussion. There are almost 100 private universities and many other institutions of higher studies in Bangladesh. These Institutions run according to their own whims and caprice. The owners who are known as governors hail in business world ranging from restaurants business to garments and other retails shops. The business natures are not concern but the owners mental faculty are same as are in the business while they are in education dealings. The common and regular systems of hiring personnel for these Institutions are based on public university / college / army retired staff $f$ or a position like Vice Chancellor and Registrar, they are either in original job or get on lien meaning holding two jobs. Govt jobs are very regular pattern and bureuoctetic positions which have no innovation, creation, modern development and knowledge having serious gaps of knowledge. Those who have degrees from the western countries in modern times are not preferred to top positions. They use those public staff a sign board as idol. What they know is not concern. Thus the private Institutions can not develop fast and lag behind the western education systems. All policies, rules and implementations are directed by those trademen but the top positions like VC or Registrar are used as puppet to run the show on daily basis except a few institutions like $10 \%$ which follow in real ways. They don't care about what University grant commission or the Ministry approves or disapproves. What are required syllabus, curriculum are not prime concerns? Money, earning profits are prime focus as on selling products or foods in Restaurants. Internal conflicts, chaos, fighting with each other among the stake holders are destroying the students career and education or original principles of education in the whole country.

The next roles are Police who are law enforcement agency in a country, who look after the society, who make the society safer and protect the weak against the criminals. These views are seen in reality differently. The police crimes in recent years like from 2008 become so rampant that are incredible. The police profession for all people but they act and help for particular party who are in power. They represent the ruling party and work for them only. People who have weapons and ammunitions are real powerful, indirectly terrorists and violent people. Under the mask they commit all crimes including murders, assassinations, sniper, 
abductions, usurping, extortions and tortures. It is clear that from the year 2008 to 2016 in Bangladesh nearly 3000 people from oppositions parties were killed and more were abducted. Millions of innocent people are having cases against them without any proper reasons or crimes, if they arrest people, it is their business because they can earn money from those who are victims. Police / Rapid Action Battalion (RAB) / CID are directly involved in these sorts of grave and serious heinous crimes which are reported in the Daily News Papers. Besides they also torture general people of normal incidents for payments of lodging false cases in different natures. In the name of cross fires, RAB killed thousands of people who might be criminals but without trials, they could not be allowed to kill others like animals. It is cross fires they say, but no rivals or criminals could kill a $\mathrm{RAB}$ officer or police, only police could kill criminals. Police are security forces for people who are protected by police but they use all sorts of adverse issues for making the ways of life intolerable. Customs police are almost similar in nature, they work in all ports, lands or seas. They harass passengers without reasons for bribes, charge them with double taxes or vet, snatching items of uses from passengers, create barriers to customs systems for money and the export or imports business are hampered seriously. The Traffic police control traffic jams, high ways and roads which have severe crisis in jams, people from all walks of life face similar troubles, they can not reach their destination in time belayed for 1 to 2 hours . Due to negligence, indifference, shirking of duties, running after bribes from drivers ignorance make all situations worse in the service.

We see the next one- Lawyers and Judges who decide justice systems and save the social structures of good and bad cultures for the criminality and innocence of people. The court situations are worse than any other professional roles. The majority cases are lodged in court are falsified, forged and faked. The decisions made by Judges based on political or sexual orientation means female is favored with favoritism. If the cases against females, case result is nothing and case is not even taken by the court or police. They believe that females must not commit crimes. If the case is against male, the case is highly focused and result is many times imprisonment of the accused without any trial. Women cases like rape, sexual harassment, teasing, dowry(money) claimed by husband, torture by husband are all falsified and minted intentionally to victimize the opposite group. The cases are $90 \%$ falsified that are women cases against men, political cases are similar like this category. Political cases are not but focus on rival members to destroy them and retain in prisons for vote advantages. Land disputes, murders cased or other sorts are $30 \%$ false. As a result this professional practice is core for making laws polluted and practicing them in society callously. Law is a backbone of a nation but the back bone is collapsed. The whole systems of justice rules are prejudiced either based on political favor, or female sex, or monetary power. These situation ns are not merely stories but serious social cries of millions of voices and souls haunt those who are responsible for their deed will be revenged.
Judges play their roles basing on either female sexism or political ties or monetary motives. This is why the country laws are made and decided in practices. Government agencies or departments offer many advantages and concessions for women to lodge cases against men or youth without money or fees, that means encouraging them to sue men for even small issues in family or society. There are many many organizations like NGOs and Ministry of Women wings work for women and creating huge discrimination issues which create chaos and turbulence in the country. Such injustice done to innocent class can not be wiped away. These have reaction and voices ultimately.

Administrators who are mainly Ministers, Secretaries, Registrars, Directors, Heads and Managers in Governments offices are seriously responsible for many sorts of corruptions in the country. They control all parts of administration of the country; they have strong influences over roles of Ministers who come to offices like guests. They decide policies, rules, laws and systems for the country; they are aware of all occurrences whenever something take place. They are directly not involved in crimes but middleman help them commit crimes. Their crimes are bribery, unfair employments, financial embezzlements, replacements of positions, victimizing someone and using mercenary for killing others. The administrators are mainly working in set routine jobs due to their obsolete knowledge and educations, lacking in modern knowledge and thus the country receive from them nothing except their folly, ego, abuse and show of power. Politicians who are real persons for a country are backbones who lead people to developments and progress. In case of Bangladesh the scenario is opposite, people support them, offer funds, services and all facilities. The most corrupt parts of all parties in dealing with national functions hinge on politicians. They are influential and dominant on issues like money, power and authority use which are prime objectives of all politicians in Bangladesh. They come from various backgrounds and bases with or without educations. They control thugs, musclemen and hooligans to protect them and use them for all purposes. They use the students for their objectives of gain and make them one sort of terrorists. Once they are selected or elected as MP or Ministers, they are out of social touch but before they assure all hopes for help and cooperation. They spend money, power and other means to stay in power. The tensions and terrorism in country are basically created by them in league with other external parties and agents. The major criminal deeds seem to be identical with their forces like murder, assassination, abductions usurping lands, extortions, though they directly are not involved in many issues. All job selections are based on political influences mean most candidates are selected for position in high ranks are political candidates who later work for ruling class, not for common people at large.

Women roles are also measured for finding the real issue of crimes. Women are almost half of population who are not out of criminal deeds. Bangladesh where a prime minister is woman, opposite leader is women and speaker is woman and 
third party leader is woman. It is a funny and ridiculous show on earth should be in Greenwich records. It crossed the worst records of feminism cultures and rules which are sternly seen in the UK and other European countries where feminism is a core norm and where males are victims for much opportunities. Men are made to act female roles. Women maneuver here in Bangladesh many opportunities of which many abuses or misuses are commonly found. The govt offers free education for girls up to degree educations and jobs offers are huge, any law suit is lodged by women work instantly without any second thought. Law suits based on women torture, by men, sexual harassment by men, and dowry claim by men from women are hot cases in Bangladesh. These law suits are $90 \%$ false. Many women get married to men who might be very poor men must pay nearly 5/6000 Euros mean 5/600000.00 taka which are very big amount as security money for women and if the husband is rich man, the security money from 10000 Euros to 30000 Euros. After a few months of marriage, Women divorce husbands, they get the amount of security money which are means and ruses of business which are repetitively followed by them in 10 years times. Women are dependent on men for all supports except child birth. Men are totally shaken and shattered by the burden of women who need helps from cradle to death. These are performed by father, brother or husband or friend or colleague. The contribution made by women are additional and subsidiary not main like food production, shelter, production or transportation and farming which run by men mainly and fit the world and feed humans. Crimes commitments by women are seen by many as minor or not important but these crimes sometimes create so worse havoc that destroy men's lives with many relatives. The crimes committed by women are adultery, eloping with concubines, claiming huge amount of moharana means security money, false lawsuits of pretended rapes, sexual harassments and tortures which destroy thousands of men and youths remaining in jails years after years, , spying, wasting money for luxuries $\&$ cosmetics, blacking mailing, hiding husband money and assets sent to father house, assassination, idle without work, folly, casting spell on young boys or males with their nude parts of body, tantalizing offers and pretext of sex which make youth addicted and insane and distracted from main paths are serious crimes. Thousands of children are made orphans now days. The children lose their parents mainly father who leads a family and mould child's career but they face a life of utter misery. $20 \%$ women are directly responsible for $15 \%$ children's (ages from 0 to 5 years) disabilities, deaths and sickness due to their utter carelessness, jobs, fashions addict, ignorance, superstitions, and arrogances. The country hugely suffers from feminists perverted policies and rules which beget all sorts of discriminations in national level of development. The focus on only female promotion for last 25 years has made the nation crippled and broken without core value and philosophy. This system is supported and led by foreign godfathers driven from back side. Unprecedented phenomenon of such ridiculous rule of feminism on Earth is rarely found. Majority people are kept in darkness for making policies and implementation of those issues of prejudices. Many important roles held by immature women lead the situations to messing up and unruly roles in contexts. They mean women depend on men for all issues including security, decisions and plans. Those males who are in power and work as influential ones are stooges, worshipers and followers of the goddess and adoring the bottoms of their Idol. They are happy people because they can use a puppet as symbol of power while they mould all power or opportunities though these become chaotic and disordered at last. General belief is that women are weak and innocent are true but time has changed, they learn bad effects and actions ignoring the good practices. They are like parasite opportunists who enjoy all power and opportunities without pain and labor. The deadliest venomous epidemic of feminism invades on the modern societies not only in this but many other countries at large.

Jail administrators in Jail situations of Bangladesh are inhuman. It is a place for criminals for punishments but the situations are worse than punishments. There are no any laws, rules and safety. In a room of 10 jail mates living, there nearly 50 jail mates are made to sleep and the washrooms or toilets are beyond descriptions. People eat and discharge their excretes in the same room and smell of all these dirt spread everywhere. Human rights are violated terribly. Thousands of innocent people who are in jails pass years after years without trials or traces. Two categories of the accused are more in numbers are political and women made cases are $90 \%$. No human rights groups or democracy activists or journalists have their consciences to treat the contexts with human voices and empathy. Beasts in jungles take mercy on the helpless while humans are worse than beasts in many contexts for own benefits.

Leadership which is another professional role in the country is a core fact and issue which must be realized by her people. There has been almost 25 years since female leaders begun to rule. The contexts in politics worsen on and on. If the leader is not followed, directed, and defended by juniors, others or parasites, or colleagues, no real decisions or results could be obtained. A leader must predict, usher, beef up, innovate and create his own policies for the country and lead the team with stern rules but the situations are not like that of rule to be applied because the original merits and competence are absent. The objectives cannot be achieved. The third parties are happy to see these conditions and have enormous scopes for making the situations worse and the worst ones which were experienced by the people several times in the past. Subordinates take the roles of the leadership. It is so frail leadership in Bangladesh that the nub of the nation is shattered and shared by aliens. The crimes situations remain the same because of leadership in various phases that are led by a leader who is worthless. Without a proficient leader, no development, peace stability, independence from aliens are possible. The leader must have 
high education, experience, foresight, humanity, proactive ability, leadership capabilities and nationalism which can make the country progress and advance. Once top leader is frail, all other leaders of different layers must not function and the consequences are failures in all efforts. The county moves forward due to a set system and the public efforts which drag the country to the positions of international paces. Private concerns are progressing well as the global business move faster. There is no stable field or position of business in the country by which the country boasts of her wealth. Many strange decisions are made and taken and used by the leader to ensure the next stay in power overlooking the future of the country and its people. Rejoicing in achievement of honours or medal got in foreign land for an issue of less importance can not be appreciated because the country has enormous basic crisis like infrastructures, environmental problems of hygiene, safety, slums and homeless people, who live in worse situation than animals live, unemployment, foreign donation and loan dependency, corruption in every vein, rights violations for lives, and basic mismanagement.

Roles of religions, cultures, economics and educations play very vital roles in constructing over all developments. The prime concerns are fanaticism or bigotry which are born in ignorance that determines cultural and economical frame works. Main religion in this country is Muslim dominated and other religions are less though, they are reflected in functions of work. Cultural frameworks are being changed due to Western developments and thrust but roots of cultures remain the same as these are deeply rooted. They move on routine and set systems of influencing others. People seem to be egoistic, selfish, avid, greedy, prone to crimes, emotional, grudgeful, malicious, tyrannical and exploitive. The developments are happening which are very transient and based on gimmicks which must not last long. These have no roots and reasons. $40 \%$ people live under extreme poverty which is compared with those in Africa like Ethiopia, Sudan. These people have no houses, work, even slums to live but staying in streets with animals, dogs and pigs. NGOs. Human right works groups, political parties, ruling class and opulent class must talk about them for settlements. There are many rich men who can instantly solve this crisis. Bangladesh has no Ministry for Human Resources Development but ministry of Women and Children which seems to work on making men eunuch rather than skilled .

Departments of governments are to be seen as places of crime sources. Some departments are pioneers in crimes and corruptions which are placed consequently from top rating to bottom, worst to lesser.

Ministries / Department of Law

Departments / Home Ministry / of Police,

Departments / Ministries of Women

Departments / Ministries of Education

Departments / Ministries of Finance and Budgets

Departments / Ministries of Information

Departments / Ministries of Transports or Communication Departments / Ministries of Civil service Commissions Departments / Ministries of Commerce and Industry
Departments / Ministries of Local Government.

Departments / Ministries of Health

Departments / Ministries of Defense

Departments / Ministries of Religion

These are major departments are linked with public dealings.

\section{The professional positions are now considered consequently from top category to bottom ones.}

Administrators, larger scales $65 \%$ personnel crimes commitments.

Ministers, larger scale $55 \%$ personnel crimes commitments.

Politicians, Medium scales $60 \%$ personnel crimes commitments.

Police, ( RAB is worst, ACC is Worse, Cops are bad, DB /CID is bad)

larger and medium scales $70 \%$ personnel crimes commitments

Judges / Lawyers , larger and medium scales 55\% personnel crime commitments

Businessmen ( big ones ) larger scales 55\% personnel crime commitments

Journalists, medium scales $45 \%$ personnel crime commitments

Bankers / Finance Heads, medium scales $45 \%$ personnel crime commitments

Doctors, medium scales $55 \%$ personnel crimes commitments

Engineers, medium scales $60 \%$ personnel crimes commitments

Contractors, medium scales $50 \%$ personnel crimes commitments

Social Workers, smaller scales $45 \%$ personnel crimes commitments

Businessmen small ones, smaller scales $70 \%$ personnel crimes commitments

Army, smaller scales $20 \%$ personnel crimes commitments Navy, smaller scales $15 \%$ personnel crimes commitments

Air Force, smaller scales $15 \%$ personnel crimes commitments

Nurses, smaller scales $30 \%$ crimes commitments

Secretary / Clark, smaller scales $45 \%$ crimes commitments

Accountants, smaller scales $50 \%$ crimes commitments

Sales Persons, smaller scales $40 \%$ crimes commitments

Teachers, smaller scales, $15 \%$ personnel crime commitments

Clergymen, smaller scales $5 \%$ crimes commitments

\section{The following are social classes of genders :}

Men, large, medium, small scales crimes $60 \%$ commitments

Women, medium and smaller scales crimes $45 \%$ commitments

Youth, (boys 20\% and girls 10\%) medium and smaller scales $30 \%$ felony/ offences commitments. 


\section{Critical Discussion}

The study topic is a very wide field of study needs ample analysis and investigations. We have tried our best to cover significant issues briefly which are dominant factors entangled with various sections and activities of people. The study methods are also used in limited scopes and means. Fundamental aspects of corruptions are touched upon describing and presenting them in real scenarios. Criminology and legal implications are brought forward from practical grounds. Different professional practices are focused on importance basis and less serious involvements professional's routes are not analyzed in broader ways. The depictions in crimes presented here are known and grasped by thousands of aware citizens of the country but on account of their personal lacks of motivations in social supports, they act as it is in the writing. If we look at the Western societies where people feel for their fellow citizens more than their lives, they talk and fight hard against ills and odds without compromises but here in Bangladesh people are sold for a cup of tea and hired for any commitments of crimes. There are some uses of language which are severely rude and indecent but these deserve for those are criticized. Uses of normal language no more appeal and carry importance for the writing. Many of us hide real issues of crime in society for decency and politeness which are pampered in a real sense of work.

\section{Methods of this Study}

At first I have try to clarify the research philosophy based on it. There are some objectives and questions with some problems to be addressed during the session of the study. I then identify several types of research approach and strategies which are main to be traced down. The research types may include descriptive or analytical, applied or fundamental, qualitative or quantitative, conceptual or empirical but two types can be integrated. The research approach shows a few issues including inductive or deductive, and qualitative or quantitative methods may be chosen for my research based on the contexts of the topic. The research strategies are survey, case studies, explanatory, exploratory, experimental, longitudinal, cross sectional, descriptive are a few chosen accordingly. The phases of research study followed as literature review, data collection, data analysis are primary stages. There are some research paradigm / parameters to be identified at this stage. The variables such as independent and dependent variables are important to clarify. . Some other variables like extraneous, control, confounded, hypothesis and experimental hypothesis testing variables must be classified at the same time while doing other work. The research design and process are followed in the phase. Statistical measurements like central tendency, measure of dispersion, skewness, kurtosis are part and parcel for analyzing data of quantitative methods. The research design indicate all other requirements such as data collection, and analysis, time scales, financial supports are important to be pointed out. Sampling and hypothesis testing are dominant issue to be completed. Tests like T test, Chi Square Test, F Test, are very import to find the significance in sampling and hypothesis results. Data interpretation and the repot writing are the final stages where finding of the research is to be clear and presented before a panel of experts. However, there is another issue that is research ethic must be maintained thoroughly while conducting the study.

\section{Conclusions}

We have attempted to examine this brief research topic for understanding various complex issues of corruptions and crimes are perpetuated in Bangladesh where the most people more or less are channeled with corruptions. The study indicates enormous links of forces and agents with government body related to worsen the normal safe environments in different parts of departments and the country as the study has thoroughly been conducted. It is more vivid to anticipate the ongoing contexts of crimes in the most professional and occupational routes. Many professions which are sunk into crimes have been exposed here in this study which spares no pains to investigate other social frame works and layers to track down the root of vices. A few professions at the top rate of occurrences in such issue have appeared before us. Mass community who are majority involved in complex mechanisms of laws and Govt carry some sorts of responsibilities for being loose and callous in dealing with such crux in society demands a severe criticism. A final hint for recovery from all odds and crux has also been offered in the writing.

\section{Recommendation}

It is really hard to comment on suggestions for further improvements on social phenomenon. It is because of the people of this country who are far from social awareness of these all facts need very genuine education, honesty, patriotic zeal, and communal harmony which can cure the minds and hearts of people to run as a proud and glorious nation. They need to love the nation and realize the outer bad influences which invite all patterns of chaos and tensions. Feminism in form of democracy and Human rights or other soft services need to be controlled for balanced development and cultures. The citizens must be learned really but ill learned meant to be stooges. The country must have an ideal leader who leads his /her subjects who can be emancipated from all evil influences. The country requires a competent leader with a team of similar skills and qualities. Our long cherished hope is to seek and find either a natural born or a man made leader who can rescue this nation from the wrath of god fathers. This writing can be imitated for further developments and changes of perspectives in the country. It 
might help many prolific writers who are dedicated to this type of research work to extend their wider scopes for writings.

\section{REFERENCES}

[1] Rahman et al. Dhaka: Center for Criminological Research, Bangladesh. Faruk, Omar, and Khatun Nurjahan. 2008. Crime Index Bangladesh 2007. Dhaka: Academic Press and Publishers, Library.

[2] Flowers, Ronald B. 1995., Female crime, criminals, and cellmates: An exploration of female criminality and delinquency, Pearson.

[3] Mcfarland Harper, Gary W., and W. LaVome Robi nson. 2010. "Pathways to Risk among inner city African -American adolescent females: The influence of Gang Membership." American Journal of Community Psychology 383 - 404 Henggeler.
[4] W., James Edwards, and Charles M. Borduin. 1987. "The Family relation s of female juvenile delinquents." Journal of Abnormal Child Psychology 15(2): 199 - 909. Herrington,

[5] Victoria, and Claire Nee. 2005. "Self - Perception, Masculinity and Female Offenders.

[6] E Hagan, Frank, 2013, 2 $2^{\text {nd }}$ Edition, , Introduction to Criminology, p.p 15 - 20, published by Sage Publisher,

[7] Phillips, Cathy, 2007, “Criminology “ Journal of Criminology published by Willam Publishing.

[8] Marsh, Ian and Gary, 2014, $2^{\text {nd }}$ Edition, Crime Justice and Media, Published by Rutledge Publishing.

[9] Pakes, Franscis, 2014, $3^{\text {rd }}$ Edition, Comparative Criminal Justice, p.p $20-24$, published by Rutledge Publishing.

[10] Van, Montgomery , Lisa, 2007, $2^{\text {nd }}$ Edition, Administration Leadership in Public Sector, p.p 50-57, Published by M E Sharpe Publishing, 